\title{
SUCCESS WITH PENILE PROSTHESIS FROM
}

\section{PATIENT'S VIEWPOINT}

JAY B. HOLLANDER, M.D.

ANANIAS C. DIOKNO, M.D.

From the Section of Urology, Department of Surgery,

University of Michigan, Ann Arbor, Michigan

\begin{abstract}
This study is designed to explore the patient's point of view on success with penile prosthesis. Detailed questionnaires were sent to 57 penile prosthesis recipients, 38 of whom responded. Overall, 89 per cent claimed improved sexual satisfaction, and 76 per cent noted improved self-image with their prostheses. Seventy-six per cent claimed their partners approved of the prosthetic device. Prosthetic appearance was satisfactory to 87 per cent. Five patients, knowing what they now know, would not have had the prosthetic implantation. A significant factor in 4 of the 5 patients was lack of partner approval. We conclude penile prosthesis implantation is successful in returning satisfactory sexual intercourse to impotent men and their partners. Partners of those desiring penile prosthesis should be included in the preoperative evaluation process.
\end{abstract}

Implantation of penile prosthesis is the most common procedure presently employed by urologists to restore ability to have sexual intercourse to impotent men and their partners. Surgical techniques and complications and comparisons of prosthesis types have been well reported. ${ }^{1-5}$ Surgical success largely has been measured by low complication rate and lack of formal patient complaint. Few have attempted to find out how satisfied penile prosthesis recipients and their partners really are. Although our complication rates and cosmetic results have compared favorably to others reported, we believe surgical success should also be judged by patient and partner satisfaction with the device. Herein we report our findings on the patient's point of view of success with penile prosthesis.

\section{Material and Methods}

By computer retrieval we obtained names and addresses of 57 consecutive patients who had undergone successful penile prosthesis placement no later than December, 1980, on our private urology service. A 104-item questionnaire developed by the authors was sent to each patient, and 38 patients responded. Data were tabulated, charts of all responders reviewed, and results analyzed. The questionnaire contained yes/no questions regarding the patient's impotence history. Multiple choice questions were used to compare current sexual satisfaction with that before prosthesis, i.e., vastly improved, mildly improved, same, or decreased. If improved or not, patients could select from appropriate lists regarding why. A similar format was used to ask the patient to estimate his partner's approval of the device and how he felt his self-image was affected. $\mathrm{Pa}$ tients were then asked to comment on the quality of the prosthetic erection. Finally, patients were asked if they would have gone through the operation knowing beforehand what they know now.

Prostheses had been placed after initial history and physical examination by the senior author. Psychiatric consultation, not a preoperative prerequisite, was used with 53 per 
TABLE: I. Probable etiology of impotence

\begin{tabular}{lc}
\hline \multicolumn{1}{c}{ Cause } & No. of Pts. \\
\hline Diabetes mellitus & 14 \\
Pelvic surgical procedure & 8 \\
Trauma & 4 \\
Neurologic disease & 4 \\
Peripheral vascular disease & 3 \\
Priapism & 2 \\
Psychogenic & 3 \\
\hline
\end{tabular}

cent of patients as an adjunct in assessing patients' stability and motivation.

\section{Results}

Twenty Scott inflatable penile prosthesis (IPP) and 18 semirigid prostheses (SR), either Small-Carrion or Finncy types, werc placed in the 38 responders. The average length of follow-up was 31.7 months and ranged from three months to 7.5 years. The average patient age at the time of follow-up was 50.5 years overall, and 46 years for the IPP group versus 55 years for the SR group. Table I shows the etiology of impotence breakdown.

Eighty-nine per cent of respondents claimed improved sexual satisfaction after prosthesis, with 67 per cent of these noting vast improvement. Ninety-five per cent of IPP patients noted improvement, compared with 83 per cent of the semirigid group. Of choices given the patient for why his sex life had improved, the four most common reasons chosen were: (1) the implant itself, (2) easier insertion of the penis into the vagina, (3) partner expresses more satisfaction with sex, (4) duration of intercourse is longer. Partner dissatisfaction, pain, and continued difficulty with insertion were reasons why overall 4 patients were dissatisfied with their sex life after prosthesis.

Seventy-six per cent of patients claimed their partners approved of the prosthesis, with 68 per cent of these partners strongly approving. Only 8 per cent of partners disliked the device. Partner approval was 80 per cent for the IPP group and 72 per cent for the SR group. The most common reasons for presumed partner ap- proval were: (1) she says so openly, (2) sex is more frequent, (3) she is more sexually aroused, and (4) she reaches orgasm more easily.

Reasons given why 8 per cent of patients felt their partner disapproved of the device included dissatisfaction with the size and length, less frequent sex, partner has less orgasm, and partner felt the device was unnatural.

Seventy-six per cent of patients claimed their self-image was improved with the device, and only 5 per cent claimed their self-image was worse after penile prosthesis placement. Ninety-six per cent of those with improved selfimage attributed this directly to the device itself. They claimed less worries about sexual performance, fceling that you can satisfy a woman, and more confidence with women contributed to improved self-image.

When asked if they would have gone through the operation given what they know now, 82 per cent said yes, 13 per cent said no, and 5 per cent did not respond. Eighty-five per cent of IPP patients and 77 per cent of SR patients said they would go through the procedure again.

Patients were asked if the quality of prosthetic erection was satisfactory (Table II). Eighty-seven per cent of responders were satisfied with overall appearance (88\% IPP, $86 \%$ SR). When cosmetic appearance was broken down into individual parameters of length, width, and firmness, patients were least satisfied with length.

\section{Comment}

Our results compare favorably with others. Kaufman et al. ${ }^{6}$ reported 78 per cent of patients with Small-Carrion devices were somewhat or completely satisfied. Gerstenberger, Osbourne, and Furlow ${ }^{7}$ found 75 per cent initial patient satisfaction with inflatable prosthesis, but after corrections of mechanical prosthesis problems they were able to show 89 per cent satisfaction. Our study had an average patient follow-up of over two and one-half years, and no doubt the correction of mechanical complications of our devices has resulted in increased patient satisfaction. No patient in our study claimed his

TABLE II. Satisfaction with quality of prosthetic erection

\begin{tabular}{|c|c|c|c|c|c|c|}
\hline Prosthesis & Inflatable & Small-Carrion & + & Finney & $=$ & Semirigid \\
\hline Length & $10 / 19=53 \%$ & $4 / 9$ & & $3 / 4$ & & $7 / 13=54 \%$ \\
\hline Width & $16 / 18=88 \%$ & $5 / 9$ & & $3 / 4$ & & $8 / 13=62 \%$ \\
\hline Firmness & $18 / 19=95 \%$ & $6 / 10$ & & $4 / 5$ & & $10 / 15=66 \%$ \\
\hline Overall appearance & $16 / 18=88 \%$ & $8 / 9$ & & $4 / 5$ & & $12 / 14=86 \%$ \\
\hline
\end{tabular}


TABLE III. Who have we failed to help?

\begin{tabular}{|c|c|c|c|c|c|c|}
\hline & & & & -Patient & & \\
\hline & 1 & 2 & 3 & 4 & 5 & 6 \\
\hline Prosthesis & SR & SR & SR & IPP & IPP & IPP \\
\hline Etiology & AODM* & AODM & AODM & AODM & Spina bifida & AODM \\
\hline Psychologic evaluation preop. & Yes & No & No & Yes & Yes & Yes \\
\hline Sex life & Worse & Worse & Worse & Improved & Worse & Improved \\
\hline Go through OR again? & No & No & ? & No & No & No \\
\hline Explanations: & & & & & & \\
\hline Insertion still a problem & $\mathrm{X}$ & $\mathrm{X}$ & & & & \\
\hline Pain & & & $\mathrm{X}$ & $\mathrm{X}$ & & \\
\hline Not firm/long enough & $\mathrm{X}$ & $\mathrm{X}$ & & & & $\mathrm{x}$ \\
\hline Partner disapproval & $\mathrm{X}$ & $\mathrm{X}$ & & & $\mathrm{X}$ & $\mathrm{X}$ \\
\hline
\end{tabular}

${ }^{*} \mathrm{AODM}=$ adult onset diabetes mellitus.

dissatisfaction was related to device malfunction. Gerstenberger et al. ${ }^{7}$ also reported 74 per cent partner satisfaction with inflatable prosthesis, similar to our findings.

Instructive in our survey was the analysis of those patients who were dissatisfied after penile prosthesis implantation. As shown in Table III, 6 patients were considered surgical failures, not because of complications but rather because they were either sexually dissatisfied after the procedure or would not have gone through the procedure in the first place given what they now know. Half were IPP and half were SR recipients. Most were diabetic and two-thirds had preoperative psychiatric evaluation with recommendation for prosthesis. All were considered organically impotent preoperatively. Two patients have apparently been left impotent despite their prostheses, as evidenced by continued difficulty with insertion, a penis not long or firm enough, and partner disapproval. Two patients are bothered by pain which is not related to infection or objective inflammation, the exact nature of which remains enigmatic. The final 2 patients were dissatisfied primarily because of partner disapproval. One whose partner left him, apparently because of the prosthesis, said, "I think she felt less of a woman because she was not the cause of erection." This is apparently a concern of many women whose partners have penile prosthesis, as reported by Kramarsky-Binkhorst. ${ }^{8}$ We believe that a dif- ferent size device may have prevented postoperative dissatisfaction of 2 patients and could have helped 2 others.

It is our conclusion that the penile prosthesis is successful in returning satisfactory sex lives to impotent men and their partners. Preoperative elective psychiatric referral for both patient and partner may be helpful. Interviewing patient and partner preoperatively with clear explanation of device types and what to expect may prevent unsatisfactory results.

Ann Arbor, Michigan 48109 (DR. HOLLANDER)

\section{References}

1. Small MP: Small-Carrion penile prosthesis: a report of 160 cases and a review of the literature, J Urol 119: 365 (1978).

2. Malloy TR, Wein AJ, and Carpiniello VL: Further experience with the inflatable penile prosthesis, ibid 122: 478 (1979).

3. Furlow WL: Surgical management of impotence using inflatable penile prosthesis: experience with 103 patients, $\mathrm{Br} \mathrm{J}$ Urol 50: 114 (1978)

4. Scott FB, et al: Erectile impotence treated with an implantable inflatable prosthesis: five years of clinical experience, JAMA 241: 2609 (1979).

5. Malloy RT, Wcin AJ, and Carpiniello VL: Comparison of inflatable penile and the Small-Carrion prosthesis in the surgical treatment of erectile impotence, J Urol 123: 678 (1980).

6. Kaufman JJ, Boxer RJ, Boxer B, and Quinn MC: Physical and psychological results of penile prostheses: a statistical survey, ibid 126: 173 (1981).

7. Gerstenberger DL, Osborne D, and Furlow WL: Inflatable penile prosthesis: follow-up study of patient-partner satisfaction, Urology 14: 583 (1979).

8. Kramarsky-Binkhorst S: Female partner perception of Small-Carrion implant, ibid 12: 545 (1978). 